Research Article

\title{
Comparison of dietary agents' garlic and bitter melon on in vitro glycation and advanced glycation end products formation
}

\author{
Gini Garima ${ }^{1}$, Neeraj Kumar Agrawal $^{2}$, Shagufta Moin ${ }^{3}$, Pankaj Kumar Gupta ${ }^{4}$
}

\begin{abstract}
${ }^{1}$ Department of Biochemistry Shaheed Hasan Khan Mewati Govt Medical College, Nalhar, Mewat (Haryana), India,

${ }^{2}$ Department of Pharmacology, Himalayan Institute of Medical Science, SRH University, Dehradun, Uttarakhand, India, ${ }^{3}$ Department of Biochemistry, J N Medical College, Aligarh Muslim University, Aligarh, Uttarpradesh, India,

${ }^{4}$ Medical Consultant, E. Z. Bioxcel Solutions Pvt Ltd, Gurgaon, Haryana, India
\end{abstract}

Received: 29 January 2016 Accepted: 11 February 2016

*Correspondence to: Dr. Neeraj Kumar Agrawal, Email: drneer80@yahoo.com

Copyright: () the author(s), publisher and licensee Medip Academy. This is an openaccess article distributed under the terms of the Creative Commons Attribution NonCommercial License, which permits unrestricted noncommercial use, distribution, and reproduction in any medium, provided the original work is properly cited.

\begin{abstract}
Background: Protein glycation is a spontaneous post translational modification of proteins by excess sugars causing formation of advanced glycation end products (AGEs) in diabetic individuals and responsible for diabetes complications. Momordica charantia L (bitter melon) and garlic have been used historically for medicinal purposes particularly for treatment of diabetes and cancers and contain potent antioxidant activity hence we planned to compare the antiglycating activities.

Methods: Human serum albumin (HSA) was used for in vitro glycation. Various concentrations of extracts of $M$. charantia $L$ and aged garlic were analyzed.

Results: Co-incubation of the $M$. charantia $L$ and aged garlic extracts with HSA-fructose mixture gives contradictory results in tryptophan fluorescence, AGE specific fluorescence and protein bound carbonyl studies.

Conclusions: $M$. charantia $L$ seems to aggravate sugar mediated glycation of the protein and need further studies to pinpoint specific bioactive compounds responsible for the observed activities whereas aged garlic seems to have strong ant glycation properties.
\end{abstract}

Keywords: AGEs, HAS, Momordica charantia L, Aged garlic

\section{INTRODUCTION}

Glycation is a spontaneous post-translational modification of proteins in which reducing sugars bind covalently to the free amino groups of proteins which leads to formation of advanced glycation end products (AGEs). ${ }^{1,2}$

AGEs contribute to the onset of several diseases such as diabetic complications, renal insufficiency, and alzheimer's disease. ${ }^{3,4}$ Recently, attention has been focused on preventing protein glycation by antioxidant from plant sources. Thus far, some compounds such as aminoguanidine, aspirin, vitamin $\mathrm{B}_{6}$, taurine, quercetin and anti-inflammatory drugs including ibuprofen, are reported to be inhibitors of the glycation reaction. ${ }^{5-10}$

Garlic (Allium sativum) has been used historically for medicinal purposes; particularly for treatment of diseases associated with ageing. ${ }^{11}$ Aged garlic extract contains 
potent antioxidant activity and is prepared from natural garlic that is aged for 20 months reducing its harsh irritating taste and odour. However, this aged garlic has a greater concentration of organo sulphur compounds such as S-allyl cysteine which is a potent antioxidant and free radical scavenger. ${ }^{12}$ Although numerous studies have demonstrated the antioxidant properties of aged garlic extract, its ability to inhibit formation of advanced glycation end products is unknown.

Similarly, Momordica charantia L. (Cucurbitaceae), commonly known as bitter gourd (bitter melon) or karela, is a tropical vegetable. It is popularly used medicinal plant in Asia, Africa and South America for treating various diseases such as diabetes and cancers. ${ }^{13-15}$ As regards to its chemical composition; it has a nonnitrogenous neutral principle charantin and on hydrolysis gives glucose and a sterol. The fruit pulp of $M$. charantia has soluble pectin but no free pectic acid. Galactouronic acid is also obtained from the pulp. M. charantia fruit contains glycosides, saponins, alkaloids, reducing sugars, resins, phenolic constituents, fixed oil and free acids. The presence of an unidentified alkaloid and 5hydroxytryptamine is also reported. The ether extract residue of the alcoholic concentrate from the leaves of $M$. charantia is reported to reveal hypoglycemic activity comparable to that of tolbutamide. ${ }^{16}$

Hence, this study was designed to analyse the effect of aged garlic and $M$. charantia $L$ extracts separately on glycation and advanced glycation end products (AGE) formation in the system.

\section{METHODS}

This study was undertaken in the Department of Biochemistry, J. N. Medical College, Aligarh Muslim University, Aligarh, Uttarpradesh, India.

\section{Materials}

Human serum albumin (HSA), dinitro phenyl hydrazine (DNPH), ethylene tetradiamine tetra-acetic acid (EDTA), coomassie brilliant blue R-250, sodium dodecyl sulphate (SDS), agarose and dialysis membranes of one inch diameter were purchased from sigma chemical company, USA. Aged garlic extract was a product of Wakunaga Pharmaceutical Company, Tokyo, Japan and $M$. charantia was purchased from a local market in Aligarh.

\section{Equipments}

Digital pH meter, type DPH-100, Shimadzu RF-5301 PC spectrofluorometer, Beckman DU-640B spectrophotometer, lyophilizer-HETO, photochem-8 colorimeter, microplate reader qualisystem PR-601, polyacrylamide gel electrophoresis assembly (Genei Bangalore) were the major equipment's used in this study.

\section{Methods \\ Isolation of plasma albumin}

Plasma albumin was isolated by the method of Tayyab and Qasim. ${ }^{17}$ Human blood was procured from the emergency operation theatre (O.T.)/blood Bank of Jawaharlal Nehru Medical College, Aligarh Muslim University, Aligarh.

\section{Determination of protein concentration}

Protein concentration was determined by the method of Lowry et al using bovine serum albumin as the standard. ${ }^{18}$ In this method of protein estimation, two reagents, namely, Folin and Ciocalteau's phenol reagent and copper reagent were used.

\section{Gel chromatography}

Sephacryl S-100 HR column was used for gel chromatography.

\section{Polyacrylamide gel electrophoresis}

Polyacrylamide gel electrophoresis of HSA was carried out in tris-glycine buffer, $\mathrm{pH} 8.3$ on $7.5 \%$ polyacrylamide gels according to the method of Laemmli. ${ }^{19}$

Sodium dodecyl sulphate polyacrylamide gel electrophoresis

Sodium dodecyl sulphate (SDS) polyacrylamide gel electrophoresis was performed by the tris-glycine buffer system of Laemmli using slab gel electrophoresis apparatus. ${ }^{19}$

\section{Staining procedures}

After the electrophoresis was complete the gels were removed and the protein bands were visualized by coomassie brilliant blue staining.

\section{Spectral analysis}

\section{Ultraviolet absorption spectroscopy}

The ultraviolet absorption spectra of native and glycated HSA samples were recorded in the wavelength range 200-400 nm on a Beckman-DU-640B spectrophotometer, using a cuvette of $1 \mathrm{~cm}$ path length. One $\mathrm{mg}$ of native and glycated HSA in a total volume of $3.0 \mathrm{ml}$ was taken for spectral analysis.

\section{Tryptophan fluorescence}

The fluorescence of tryptophan residue Trp 214 in native and glycated HSA was monitored with excitation at 285 $\mathrm{nm}$ and the emission measured over the range 290-440 
$\mathrm{nm} .^{20}$ The concentration of protein samples was taken as $100 \mu \mathrm{M}$.

Advanced glycation end products (AGEs) related fluorescence

AGEs formations were measured by determining the fluorescence by excitation at $370 \mathrm{~nm}$ and emission between 400-500 nm using Shimadzu RF-5301 PC spectrofluorophotometer. $^{21}$ The concentration of protein sample was taken as $100 \mu \mathrm{M}$.

\section{Determination of protein bound carbonyl groups}

HSA bound carbonyl groups were estimated by a published procedure. $^{22}$

\section{Determination of total phenolic content}

Total phenolic content was determined by the method of Saucier et al with slight modification and the results were expressed directly in absorbance units at $765 \mathrm{~nm} .^{23}$

\section{RESULTS}

\section{Total polyphenolic compounds}

High amount of polyphenolic compound is an indicator of antioxidant property of any plant extract. The extracts of aged garlic and $M$. charantia $L$ was found to have good amount of polyphenolic compounds $(60.3 \mathrm{mg} / \mathrm{g})$ and $(75.3 \mathrm{mg} / \mathrm{g})$ respectively.

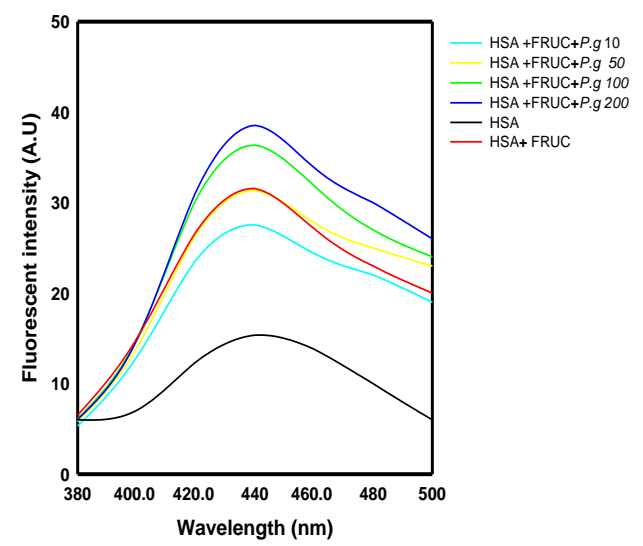

\section{Tryptophan fluorescence}

Hydroxyl radicals generated during glucose autoxidation induce protein fragmentation and conformational changes. Protein subjected to glycation in vitro lose tryptophan fluorescence, acquire fluorescence typical of tryptophan degradation products and lose $-\mathrm{SH}$ groups.

Glycated HSA showed decrease in fluorescent intensity as can be seen from Figure 1, glycated HSA samples treated with $M$. charantia $L$ extract showed decrease in fluorescence intensity in a dose-dependent manner, but in contrast to $M$. charantia $L$ extract, glycated HSA samples treated with Aged garlic extract showed increase in fluorescence intensity in a dose-dependent manner (Figure 1).

\section{AGE-specific fluorescence}

AGE (advanced glycation end products) has a yellow brownish pigmentation with a characteristic fluorescence pattern: excitation in the range 350-390 $\mathrm{nm}$ and fluorescence emission at 440-470 nm. AGE-specific fluorescence was found to be increased in the presence of fructose following the 21-days incubation. Presence of extract of $M$. charantia $L$ led to further increase in formation of fluorescent AGEs in a dose dependent manner whereas glycated HSA samples treated with Aged garlic extract showed a decrease in AGE-specific fluorescence in a dose-dependent manner (Figure 2).

Figure 1: Tryptophan fluorescence of HSA (human serum albumin) upon in vitro glycation in the presence and absence of $M$. charantia $L$ and aged garlic extracts.

\section{Protein bound carbonyl groups}

Protein-bound carbonyl intermediates have long been a possible route to AGEs formation. Glycation of HSA with fructose led to an increase in carbonyl content. Further, treatment of glycated HSA sample with $M$. charantia L extract was associated with increase in protein bound carbonyl groups in a dose-dependent manner but treatment of glycated HSA sample with aged garlic extract was associated with decrease in protein bound carbonyl groups in a dose-dependent manner (Figure 3). 

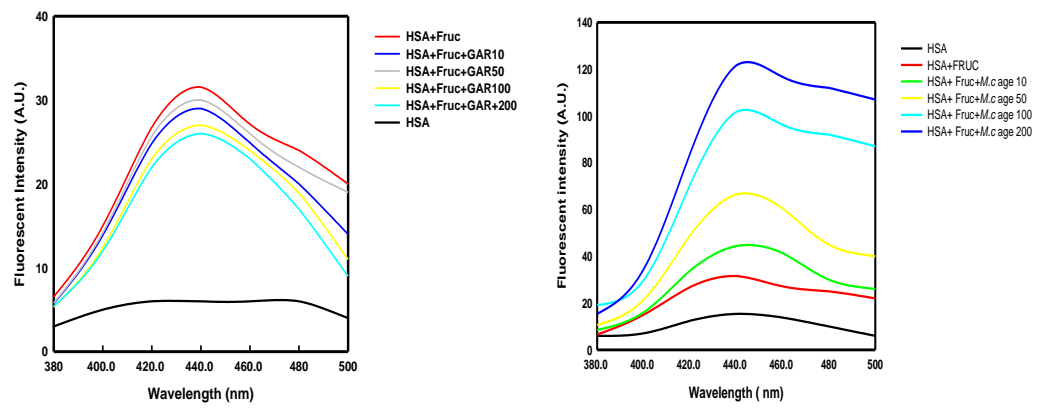

Figure 2: AGEs specific fluorescence spectra of native, glycated, $M$. charantia $L$ extract and aged garlic extract treated glycated HSA (human serum albumin) samples.
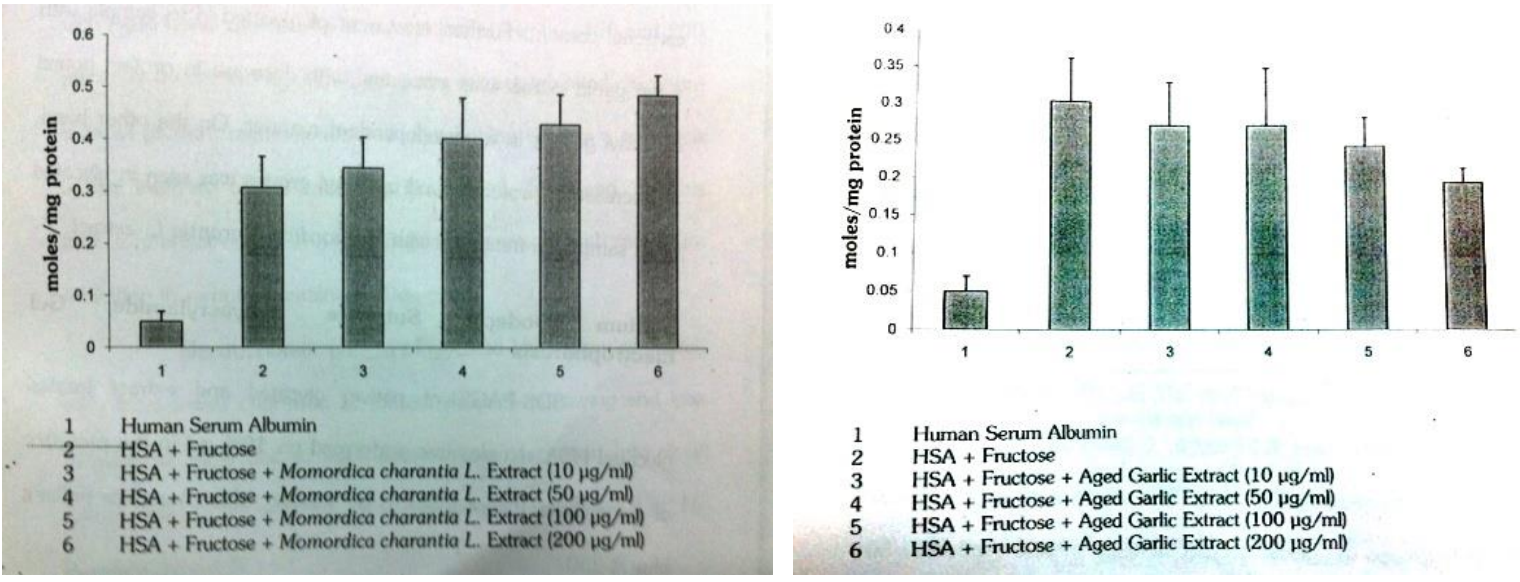

Figure 3: Determination of protein carbonyls in native, glycated, $M$. charantia $L$ and aged garlic extracts treated glycated HSA (human serum albumin) samples.
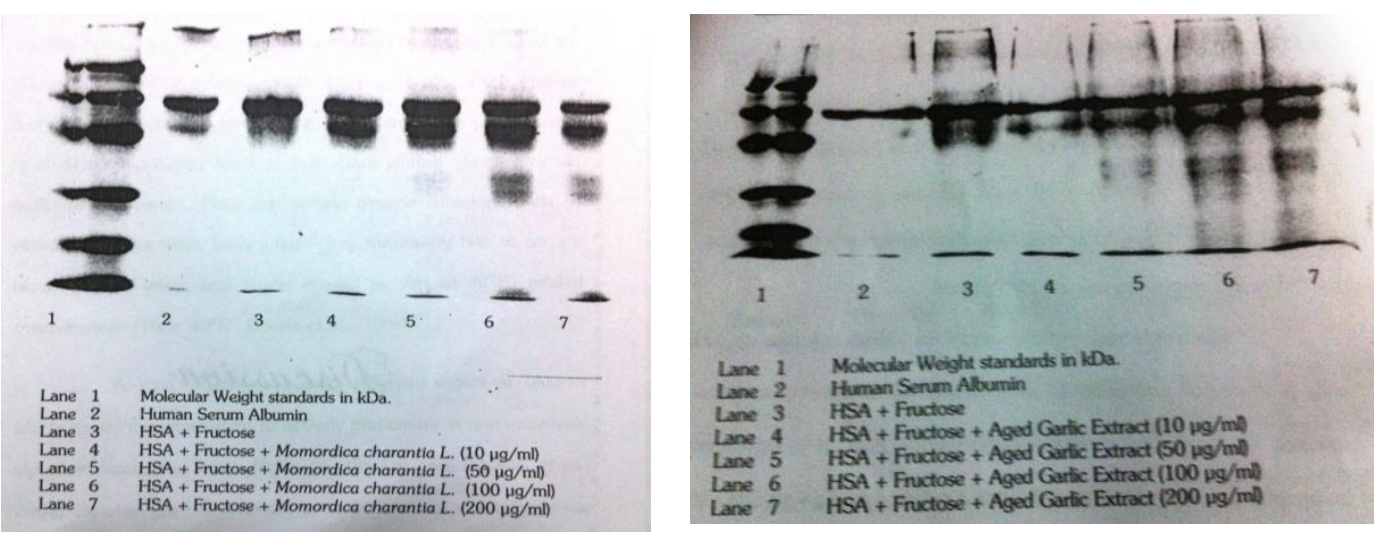

Figure 4: SDS-PAGE of HSA (human serum albumin) upon in vitro glycation in the absence and presence of $M$. charantia $L$ and aged garlic extracts. 


\section{Sodium dodecyl sulphate polyacrylamide gel (SDS- PAGE) electrophoresis}

Electrophoretic pattern of glycated HSA samples treated with $M$. charantia $\mathrm{L}$ extract showed narrowing and low intensity of band at a concentration of 10, 50, 100 and $200 \mu \mathrm{g} / \mathrm{ml}$. M. charantia L extract inhibited glycationinduced protein fragmentation and cross-linking causing a reduction in the intensity of the band. This inhibitory effect occurs in a dose-dependent manner with maximum inhibition in samples containing $200 \mu \mathrm{g} / \mathrm{ml}$, similar pattern has also been shown by aged garlic extract (Figure 4).

\section{DISCUSSION}

Interaction of proteins with sugars results in structural modification of the former that ultimately lead to formation of AGEs. ${ }^{1,2,24}$ Higher animals have evolved various strategies to maintain the plasma sugar level thereby avoiding such complications during life-time of an individual. However, there are certain disease situations such as diabetes mellitus when body's regulatory machinery fails to control blood glucose levels and finally ensued in various AGEs related complications. ${ }^{3,25}$

In the present study we have studied effect of aged garlic and $M$. charantia $L$ extracts separately on fructose mediated glycation of model protein human serum albumin.

The data of the present study suggest that co-incubation of the $M$. charantia $L$ extract with HSA-fructose mixture intensify the fructose mediated glycation of HSA. The tryptophan fluorescence studies revealed that $M$. charantia $L$ further decreases fluorescence intensity of the fructose treated HSA in dose-dependent manner. It seems that $M$. charantia $L$ extract causes conformational changes in the HSA structure that ultimately leads to further burying of the tryptophan residues. AGE related fluorescence and protein bound carbonyl compound formation studies further confirms above observations and suggests that $M$. charantia $L$ enhances AGEs formation that ultimately results in increase in fluorescent intensity. In contrast, co-incubation of the aged garlic extract with HSA-fructose mixture inhibits the fructose mediated glycation of HSA which is revealed by increased fluorescence intensity in tryptophan fluorescence studies, decrease fluorescence intensity in dose dependent manner in AGE related fluorescence and decrease in protein bound carbonyl compound formation.

Incidentally, both $M$. charantia $L$ and aged garlic extracts were found to have high amount of polyphenolic compound that indicates antioxidant property of both herbs, but results have revealed antioxidant property more in favour of aged garlic extract and ironically $M$. charantia $L$ extract was found to be pro glycation herb in most of the in vitro methods except SDS-PAGE analysis where it has shown similar results like aged garlic extract.

The observed effect of aged garlic extract on inhibition of fructose mediated modification of HSA could be explained on the basis of anti-oxidative property of garlic extract. Garlic has been reported to be a rich source of allyl sulphides such as diallylsulphide, diallyldisulphide and diallyltrisulphide (formed from allicin). Oxidation processes are important in the formation of many AGEs. It seems garlic components help in inhibition of autooxidation of fructose and thereby suppress formation of highly reactive dicarbonyl compounds. ${ }^{26}$

The observed pro-glycating properties of $M$. charantia $L$ extract induce a sense of precaution as $M$. charantia $L$ has been reported to possess strong anti-diabetic effect. This study clearly suggest that, antidiabetic effect of $M$. charantia $L$ may be at the insulin-sugar interaction level, however some of its components can aggravate sugar mediated glycation and degradation of various proteins of the living cells.

It has been concluded that $M$. charantia $L$ seems to aggravate sugar mediated glycation of the protein and need further studies to pinpoint specific bioactive compounds responsible for the observed activities, on the contrary, aged garlic extract was found to have a strong antioxidant property which is revealed by anti-glycation of protein and decrease AGEs formation in different in vitro studies.

\section{ACKNOWLEDGMENTS}

The authors are thankful to laboratory technicians of Department of Biochemistry, AMU, Aligarh for helpingout of successfully completion of this study.

Funding: No funding sources

Conflict of interest: None declared

Ethical approval: Not Required

\section{REFERENCES}

1. Ahmed N. Advanced glycation endproducts-role in pathology of diabetic complications. Diabetes Res. Clin Pract. 2005;67:3-21.

2. Voziyan PA, Khalifah RG, Thibaudeau C, Yildiz A, Jacob J, Serianni AS, Hudson BG. Modification of proteins in vitro by physiological levels of glucose: pyridoxamine inhibits conversion of Amadori intermediate to advanced glycation end-products through binding of redox metal ions. J Biol Chem. 2003;278(47):46616-24.

3. Bucala R, Makita Z, Vega G, Grundy S, Koschinsky T, Cerami A, Vlassara H. Modification of low density lipoprotein by advanced glycation end products contributes to the dyslipidemia of diabetes and renal insufficiency. Proc Natl Acad Sci. 1994;91(20):9441-45. 
4. Vitek MP, Bhattacharya K, Glendening JM, Stopa E, Vlassara H, Bucala R, Manogue K, Cerami A. Advanced glycation end products contribute to amyloidosis in Alzheimer disease. Proc Natl Acad Sci. 1994;91(11):4766-70.

5. Brownlee M, Vlassara H, Kooney A, Ulrich P, Cerami A. Amino guanidine prevents diabetesinduced arterial wall protein cross-linking. Science. 1986;232(4758):1629-32.

6. Huby R, Harding JJ. Non-enzymic glycosylation (glycation) of lens proteins by galactose and protection by aspirin and reduced glutathione. Exp Eye Res. 1988;47:53-9.

7. Booth AA, Khalifah RG, Hudson BG. Thiamine pyrophosphate and pyridoxamine inhibit the formation of antigenic advanced glycation endproducts: comparison with aminoguanidine. Biochem Biophys Res Commun. 1996;220(1):113-9.

8. Malone JI, Lowitt S, Cook WR. Non osmotic diabetic cataracts. Pediatr Res. 1990;27:293-6.

9. Morimitsu Y, Yoshida K, Esaki S, Hirota A. Protein glycation inhibitors from thyme (Thymus vulgaris). Biosci Biotechnol Biochem.1995;59;2018-21.

10. Raza K, Harding JJ. Non-enzymic modification of lens proteins by glucose and fructose, effects of ibuprofen. Exp Eye Res. 1991;52:205-12.

11. Rahman K. Garlic and aging: new insights into an old remedy. Ageing Res Rev. 2003;2(1):39-56.

12. Imai J, Ide N, Nagae S, Moriguchi T, Matsuura $H$, Itakura Y. Antioxidant and radical scavenging effects of aged garlic extract and its constituents. Planta Med. 1994;60(5):417-20.

13. Ahmed I, Lakhani MS, Gillett M, John A, Raza H. Diabet Res Clin Pract. 2001;51:155-61.

14. Virdi J, Sivakami S, Shahani S, Suthar AC, Banavalikar MM, Biyani MK. J Ethnopharmacol. 2003;88:107-11.

15. Rotshteyn Y, Zito SW. J Ethnopharmacol. 2004;93:337-44.
16. Dhalla NS, Gupta KC, Sastry MS, Malhotra CL. Indian J Pharm. 1961;23:128.

17. Tayyab S, Qasim MA. Purification and properties of buffalo serum albumin. Biochem Int. 1990;20(2):405-15.

18. Lowry OH, Rosebrough NJ, Forr AL, Randall RJ. Protein measurement with the folin phenol reagent. J Biol Chem. 1951;193:265-75.

19. Laemmli UK. Cleavage of structural proteins during the assembly of the head of bacteriophage T4. Nature. 1970;227(5259):680-5.

20. Shaklai N, Garlick RL, Bunn HF. Nonenzymatic glycosylation of human serum albumin alters its conformation and function. $J$ Biol Chem. 1984;259:3812-7.

21. Galle J, Schneider R, Winner B, Lehmann-Bodem C. Glyc-oxidized LDL impairs endothelial function more potently than oxidized LDL: role of enhanced oxidative stress. Atherosclerosis. 1998;138(1):65-77.

22. Levine LR, Garland D, Oliver NC, Amici A, Climent I, Lenz AG et al. Determination of carbonyl content in oxidatively modified proteins. Methods Enzymol. 1990;186:464-78.

23. Saucier CT, Waterhouse AL. Synergetic activity of catechin and other antioxidants. J Agric Food Chem. 1999;47(11):4491-4.

24. Singh R, Barden A, Mori T, Beilin L. Advanced glycation end-products: a review. Diabetologia. 2001;44(2):129-46.

25. Turk Z. Advanced glycation toxicity in diabetic complications. Diabetol Croatica. 1997;26:11-26.

26. Garima G, Moin S, Agrawal NK, Gupta PK, Dwivedi S, Gupta U. A study on the role of dietary agent aged garlic extract on protein glycation. World J Pharm Res. 2015;4(9):968-76.

Cite this article as: Garima G, Agrawal NK, Moin S, Gupta PK. Comparison of dietary agents' garlic \& bitter melon on in vitro glycation and advanced glycation end products formation. Int J Basic Clin Pharmacol 2016;5:257-62. 